\title{
To Assess the Nerve Conduction Velocity Declination Rate According to Age in Median Nerve of Normal Healthy Subjects
}

\author{
Patel Gaurav J. ${ }^{1}$, Vekariya Nikunj $\mathbf{N}^{2}$ \\ ${ }^{1}$ Ahmedabad Physiotherapy College, Bopal Ghuma road, Ghuma, Ahmedabad-380058, India \\ ${ }^{2}$ Govt College of Physiotherapy, Dahod, India
}

\begin{abstract}
Background: Aging is a process that is often accompanied by physiological changes. These physiological changes include slowing in muscle contractility, alteration in muscles metabolism and neuromuscular junction and reduction in nerve conduction velocity. Age has been widely accepted to have an influence on nerve velocity. There is loss of both myelinated and unmyelinated nerve fibers. Potentially well documented effect on the function and electrophysiological properties of peripheral nerves. The most common age-related degenerative alteration is an accumulation of dark cytoplasm in pocket that is produced by splitting of the major dense line. Another but less common myelin alteration associated with aging is the formation of myelin balloons. The conduction velocities begin to decline after 30-40 years of age but the values normally change by less than 10m/s at 6th or even in 8th decade. Materials and Methods: Total 80 healthy subjects between age of 30-79 years were included in the study. They were divided into five different age groups. Subjects were excluded if they suffered from diabetes mellitus or any neurological disorders that affect nerve. The median was asses. The site of stimulation for the median motor was the wrist and elbow. The recording site for the median motor was at the abductor pollicisbrevis muscle and For the sensory conduction test of median, the site of stimulation was at the wrist. The recording was done at the index finger. A ground electrode was placed in between the stimulating and recording electrodes. The conduction distance was estimated with a flexible measuring tape. Results: The result shows statistically significant decrease in nerve conduction velocities of median with increasing age, after analyzing the data by SPSS version 20. The study shows decline in sensory nerve conduction velocity of median $S N C(0.37 \mathrm{~m} / \mathrm{s} / \mathrm{y}$ ear $)$ \& were more than motor nerve conduction velocity of median $(0.25 \mathrm{~m} / \mathrm{s} / \mathrm{year})$. Conclusion: There appears to be a significant decline in the motor and sensory conduction velocity of median with increasing age in the adult. This finding could be utilized in confirming the diagnosis of peripheral nerve diseases with clinical correlation.
\end{abstract}

Keywords: Nerve Conduction Velocity Declination Rate, Median nerve

\section{Introduction}

Ageing is a process that is often accompanied by physiological changes. The physiological changes include slowing in muscle contractibility, alteration in muscle metabolism and neuromuscular junction as well reduction in nerve conduction velocity (NCV). ${ }^{1}$ Most developed world countries have accepted the chronological age of 65 years as a definition of ,elderlye persons. As far back as 1875 in Britain the friendly societies Act, enacted the definition of old age as " any age after 50", yet pension schemes mostly used 60 or 65 years for eligibility(Roebuck 1979). The United Nation has not adopted a standard criterion but generally use more than 60 years to refer the older population (personal correspondence 2001). ${ }^{2}$ There are well documented agerelated changes that occur in central and peripheral nervous system. Studies have demonstrated that ageing affect the anatomy as well as the structural and functional properties of the peripheral nervous system. ${ }^{3}$

There is loss of both myelinated and unmyelinated nerve fibers. There is potentially well documented effect on the function and electrophysiological properties of peripheral nerves. These include a decline in nerve conduction velocity, muscle strength discrimination, autonomic responses and endoneurial blood flow. ${ }^{3}$ The peripheral nervous system as well as the central nervous system is implicated in many age dependent disorders. Functional deficits may be consequences of structural and bio chemical changes that result in a slowly progressive loss of neuron and nerve fibers. This loss is not compensated because of the decreased regenerative and innervating capabilities of nerve fiber in aged subject. ${ }^{4}$

Functional, structural and biochemical changes have been reported in peripheral nerves of aged subjects. Electrophysiological studies found lower nerve conduction velocity values in older subjects than in younger subjects. However, there are some discrepancies among reports regarding the rate of decline. Some studies showed a linear decline in nerve conduction velocities with age. ${ }^{4}$

\section{Material}

80 normal healthy individuals ranging between the ageof 30-79 years were included in study. They were divided in five group(Group 1:30-39, Group 2:40-49, Group3: 50-59, Group:4 60-69, Group 5, 70-79).Subjects were excluded if they suffered from reported History of Diabetes or any metabolic disorders, Neuromuscular disorders, Peripheral neuropathy, Cognitive impairment, History of recent Surgery. Subjects were excluded who had done smoking and alcohol consumption in last 24 hours $5,6,7,8$

With use of RMS EMG.EP MARK II (Recorder and Medicare system) the data was collected. 


\section{International Journal of Science and Research (IJSR) \\ ISSN (Online): 2319-7064}

Index Copernicus Value (2013): 6.14 | Impact Factor (2014): 5.611

\section{Method}

The subjects fulfilling the inclusion criteria were selected \&informed regarding the protocol of the study.Prior to the procedure all subject were considered for demographic data on age, height, weight, gender, dominance \& occupation. Nerve conduction velocity test had been performed on dominant upper limbs only. The test protocol was explained to the subject. The height $(\mathrm{cms})$ and weight (kgs) was recorded using stature meter and weighing machine. Skin temperature (c) was recorded through infrared thermometer. As per protocol, the body parts were cleansed with spirit before nerve conduction velocity test. The ground electrode, recording surface electrodes and stimulator were used for assessing the motor nerve conduction velocity and the ground electrode, recording ring electrode and stimulator were used for recording the sensory nerve conduction velocity. The conduction distance was measured by using flexible measuring tape. Nerve conduction velocity $(\mathrm{m} / \mathrm{sec})$ was measured by using following formula

Motor nerve conduction velocity $(\mathrm{MNCV})=\mathrm{D} / \mathrm{PL}-\mathrm{DL}$ Sensory nerve conduction velocity $(\mathrm{SNCV})=\mathrm{D} / \mathrm{L}$

Where: $-\mathrm{D}=$ distance in $\mathrm{cm}, \mathrm{PL}=$ proximal latency in $\mathrm{ms}$, $\mathrm{DL}=$ distal latency in $\mathrm{ms}$ and $\mathrm{L}=$ latency in $\mathrm{ms} .{ }^{5,6,7}$

\section{Median Motor Nerve Conduction}

The patient was positioned supine with arm abducted approximately to $45^{\circ}$ with elbow extended \& forearm supinated. The recording electrode was placed close to the motor point of abductor pollicis brevis and reference electrode was distal to it. A supramaximal stimulus was given at wrist ( $3 \mathrm{~cm}$ proximal to the distal crease) and at elbow (medial to the tendon of biceps). The conduction distance between the two stimulated points was measured by using measuring tape. $5,6,7$

\section{Median Sensory Nerve Conduction}

Sensory conduction velocity of median nerve was measured by antidromic stimulation. The patient position is same as for the median motor nerve conduction. The recording was made from ring electrode at interphalangeal joint of index finger and stimulation was given at wrist. The conduction distance between the recording and stimulating electrode was measured by using measuring tape. $^{5,6,7}$

Data was analyzed on statistical software SPSS Version 20.0 .

\section{Result}

\begin{tabular}{|c|c|c|c|c|}
\hline $\begin{array}{c}\text { Median } \\
\text { Nerve }\end{array}$ & $\begin{array}{c}\text { Conductio } \\
\text { nelocity } \\
\text { Decrease } \\
30-49\end{array}$ & $\begin{array}{c}\text { Conductio } \\
n \text { Velocity } \\
\text { Decrease } \\
30-59\end{array}$ & $\begin{array}{c}\text { Conductio } \\
\text { n Velocity } \\
\text { Decrease } \\
30-69\end{array}$ & $\begin{array}{c}\text { Conductio } \\
n \text { Velocity } \\
\text { Decrease } \\
30-79\end{array}$ \\
\hline $\begin{array}{c}\text { MNC } \\
\text { Decrease } \\
\text { m/s }\end{array}$ & 3.10 & 6.75 & 9.55 & 12.60 \\
\hline $\begin{array}{c}\text { Declinatio } \\
\text { n rate Per } \\
\text { Year }\end{array}$ & 0.16 & 0.22 & 0.24 & 0.25 \\
\hline $\begin{array}{c}\text { SNC } \\
\text { Decrease } \\
\text { m/s }\end{array}$ & 6.10 & 9.50 & 13.40 & 17.80 \\
\hline $\begin{array}{c}\text { Declinatio } \\
\mathrm{n} \mathrm{rate} \mathrm{Per} \\
\text { Year }\end{array}$ & 0.3 & 0.32 & 0.34 & 0.37 \\
\hline \multicolumn{2}{|c|}{} & & & \\
\hline
\end{tabular}

The result of this study showed that as the age advances there is a progressively decrease in the sensory nerve conduction velocity of median $(p<0.001)$, as well as in the motor nerve conduction velocity of median $(p<0.001)$

\section{Discussion}

Nerve conduction study is an important method used in clinical practices as diagnostic tool and has been thoroughly validated ${ }^{8}$.

Decline in motor and sensory nerve conduction velocity per year

\begin{tabular}{|c|c|c|}
\hline \multirow{2}{*}{ Median } & MNC & Decline per year (30-79) \\
\cline { 2 - 3 } & $\mathrm{SNC}$ & $0.25 \mathrm{~m} / \mathrm{s} /$ year \\
\hline \multirow{2}{*}{ MN } & $0.37 \mathrm{~m} / \mathrm{s} /$ year \\
\hline
\end{tabular}

The reduction in the average conduction velocity in older subjects can be explained by following factors $9,10,11,12,13$, $14,15,16$

i. Local ischemia due to vascular changes.

ii.Metabolic depression associated with changes in permeability or trans-membrane transfer mechanisms of nerve fibers.

iii.Selective degeneration of fastest conducting fibers ${ }^{17}$ iv.Decrease in axon diameter than of fibers diameter.

v.Tapering of the axon size.

vi.Morphological changes such as loss of myelinated nerve fiber, decrease in size and myelin of the remaining myelinatedfibers. $^{18}$

There is strong evidence that age and myelin integrity reduces conduction velocity along nerve fibers and the age related alteration in structure of myelin conduction velocity. ${ }^{19}$

In human peripheral nerves, it has been proved that with an increase in the age there is an increase in connective tissue and a reduction in the patency of the blood vessels. This begins in the fourth decade of life as an endothelial proliferation and hyalinization of the vessels with an increase in the endoperineurium invading and apparently replacing areas of the nerve bundles by connective tissue 


\section{International Journal of Science and Research (IJSR) \\ ISSN (Online): 2319-7064}

Index Copernicus Value (2013): 6.14 | Impact Factor (2014): 5.611

elements. This gradual reduction in blood supply and increase in connective tissue seems to be a gradual alteration and reduction of the nerve fibers, especially the larger ones. ${ }^{20}$

The current study shows, decline in sensory nerve conduction velocity of median $\mathrm{SNC}(0.37 \mathrm{~m} / \mathrm{s} /$ year $)$ was more than motor nerve conduction velocity of median $(0.25 \mathrm{~m} / \mathrm{s} /$ year $)$. These findings are correlates with the Laffratta and Canestrari (1966) who reported that sensory nerve conduction velocity and amplitude are affected more than motor fibers by aging. ${ }^{21}$

\section{Conclusion}

There appears to be a significant decline in the conduction velocity of both sensory and motor and sensory fibers of median nerves with increasing age in the adult. This finding could be utilized in confirming the diagnosis of peripheral nerve diseases with clinical correlation.

\section{References}

[1] Mohamed Saufi Awang et al; nerve conduction study of healthy Asian Malays; the influence of age on median, ulnar and sural nerve: Med SciMonit, 2007; 13(7): CR330-332.

[2] WHO; definition of an older or elderly person proposed working definition of an older in Alfred for the MD's project.

[3] R.Kyle Hanks, Ricardo Pietroban Karen C. Nielsen et al ; The effect of age on sciatic nerve block duration; international Anesthesia research society 2006; 102; 588-92.

[4] Enrique Vedu, Dolares Cebllas, Jarges J. Vilches et al; Influence of ageing on peripheral nerve function and regeneration; journal of the peripheral nervous systems;191-208(2000)

[5] U.K. Mishra J. Kalita clinical neurophysiology; nerve conduction electromyography and evoked potentials.

[6] Jun Kimura, Electrodiagnosis in diseases of nerve and muscle principles and practice 2 nd edition.

[7] Michael J Aminoff; Electro diagnosis in clinical neurology 5 th edition.

[8] Mohamed Saufi Awang, Jafri Malin Abdullah; Nerve conduction study among healthy Malays, the influence of age, height and body mass index on median, ulnar, common peroneal and sural nerves ; Malaysian journal of medical sciences vol13 num2, 2006 pp 1923.

[9] Dr.Haider Zaigham Baqai, Dr. Muhammad Tariq et al; Sural nerve conduction velocity; age related variation in our normal population. The professional vol.08, No.04 Oct, Nov, Dec, 2001.

[10]Dia Shehab et al; Normal values of lower limb nerve conduction in Kuwait; 1999;8:134-137

[11] Mark B. Bromberg et al; Symmetry of normal motor and sensory nerve conduction measurements. Muscle and Nerves 21; 498-503, 1998.

[12] William J. Hennessey, Frank J. E. Falco; Median \& ulnar nerve conduction studies: Normative data for young adults, Arch Phys Med Rehabilvol 75 March 1994.
[13]P. Bouche, F. cattrlin; Clinical \& electrophysiological nervous study of the peripheral nervous system in the elderly; J. Neurol (1993) 240:263-268.

[14] Stetson DS, Albers JW, Silverstain BA et al; Effects of age, sex and arthrophometric factors on nerve conduction measures. Muscle Nerve, 1992; 15: 1095104.

[15] Konishi $\mathrm{H}$; Motor nerve conduction studies in median and ulnar nerve in old adults over 80 years of age. Nippon Seikeigeka Gakkai Zasshi, 1982; 56(4): 30520.

[16] Dorfman LJ. Bosley TM; age-related changes in peripheral and central nerve conduction in man; Neurology 1979; 29: 38-44.

[17] Carl W. Lafratta; A study of the relationship of motor nerve conduction velocity in the adult to age, sex and handedness: Archives of Physical Medicine \& rehab. Aug- 1964

[18] Michael H. Chase; Age dependent changes in cat masseter nerve: an electrophysiological \& morphological study; Brain research vol 586 Issue 2 July 1992 pp 279-288.

[19] Alan Peters; The effect of normal aging on myelin and nerve fibers a review: Journal of Neurocytology31, 581-593 (2000).

[20] Harry H. Wilcox; change in nervous system with age; Vol 71 No.12 Dec 1956.

[21] Laffratta C.W., Canestari R.E.; a comparison of sensory and motor nerve conduction velocities as related to age: Arch Phys. Med. Rehabil 1966: 47, 286-290

\section{Author Profile}

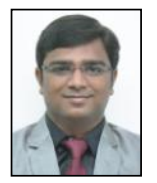

Dr. Gaurav J. Patel studied B. Physiotherapy in Govt. Physiotherapy College, Baroda, which was affiliated with Maharaja Sayajirao University, Vadodara and Master of Physiotherapy (Neuroscience) from V.S.P.M's College of Physiotherapy, Nagpur. The college was affiliated with Maharashtra University of Health Science, Nasik. Currently he is working as Principal Incharge, Ahmedabad Physiotherapy College, Ahmedabad. This is constituent College of Parul University, Vadodara. He has been also award by significant contribution Award by Indian Association of Physiotherapist in $53^{\text {th }}$ Annual conference at Shimla 2015 